\title{
Methods to study Drosophila immunity
}

\author{
Claudine Neyen*, Andrew J. Bretscher, Olivier Binggeli, Bruno Lemaitre* \\ Global Health Institute, School of Life Sciences, Ecole Polytechnique Fédérale de Lausanne (EPFL), Station 19, 1015 Lausanne, Switzerland
}

\section{A R T I C L E I N F O}

\section{Article history:}

Available online 12 March 2014

\section{Keywords:}

Drosophila

Immunity

Pathogens

Hemocytes

Antimicrobial peptide

Survival

Melanization

\begin{abstract}
A B S T R A C T
Innate immune mechanisms are well conserved throughout evolution, and many theoretical concepts, molecular pathways and gene networks are applicable to invertebrate model organisms as much as vertebrate ones. Drosophila immunity research benefits from an easily manipulated genome, a fantastic international resource of transgenic tools and over a quarter century of accumulated techniques and approaches to study innate immunity. Here we present a short collection of ways to challenge the fruit fly immune system with various pathogens and parasites, as well as read-outs to assess its functions, including cellular and humoral immune responses. Our review covers techniques for assessing the kinetics and efficiency of immune responses quantitatively and qualitatively, such as survival analysis, bacterial persistence, antimicrobial peptide gene expression, phagocytosis and melanisation assays. Finally, we offer a toolkit of Drosophila strains available to the research community for current and future research.
\end{abstract}

(c) 2014 Elsevier Inc. All rights reserved.

\section{Introduction}

The Drosophila immune system has been the focus of intense studies and is now one of the best-characterized among Metazoans. Studies show that insect immune systems are complex and share many characteristics of the vertebrate innate immune system. The nature of the Drosophila immune response is dependent on the mode of infection, the type of pathogen and route of challenge, the tissue(s) affected, developmental stage, genotype and many other physiological parameters including the presence of symbiotic bacteria. Since immune reactions are not as tightly regulated as developmental processes, specific attention to all these physiological parameters is essential before reaching any conclusion. Physiological processes have a multitude of ways of interfering with host survival to infection; as an immune response requires the rapid reallocation of resources it easily enters in competition with other vital processes [1,2]. As a consequence many immune and non-immune factors contribute to survival. Generally, any mutants that affect the general fitness of flies in some way or other tend to exhibit higher susceptibility to infection. For instance, stress and repair programs have recently entered centre stage in host defence as exemplified by accumulating work on the gut $[3,4]$.

\footnotetext{
* Corresponding authors.

E-mail addresses: claudine.neyen@epfl.ch (C. Neyen), bruno.lemaitre@epfl.ch (B. Lemaitre).
}

This also raises another point to consider when assessing immunity: the immune response is compartmentalized or tissuespecific. We traditionally distinguish the systemic immune response on one hand, which takes place in the body cavity and involves hemolymph, hemocytes and the fat body, and local immune responses on the other hand, that take place in barrier epithelia such as the gut and the tracheae [5]. Humoral and tissue-specific immunity is complemented by powerful intracellular defence mechanisms such as RNAi, which is an essential defence against virus.

In the wild, Drosophila is infected at various stage of its life cycle by viruses, parasites (nematodes, parasitoid wasps), protozoans (for example trypanosomes [6]), fungi (yeast, filamentous and Microsporidians) and bacteria. Each of these microbes triggers a rather distinct set of overlapping immune pathways. Flies are also infected by two vertically transmitted endosymbionts, Wolbachia and Spiroplasma. While there is no evidence that these highly coevolved symbionts trigger or are affected by the immune system, both classes of endosymbionts can promote symbiont-mediated defence; Wolbachia protects flies against viruses while Spiroplasma exerts protection against wasps and nematodes $[7,8]$. The presence of Wolbachia which is found in many lab stocks should be taken into consideration.

The immune response can be analysed after challenge or under basal conditions. The basal immune response is affected by environmental microbes associated with the flies such as bacteria found in the gut or ingested from the substratum. In these cases, germ-free (axenic) or gnotobiotic (i.e. with defined microbiota) fly culture allows defining the contribution of these microbes to 
the basal level of infection. The systemic immune response is traditionally divided into a cellular response that involves hemocytes and the humoral response that includes and melanisation and the production of antimicrobial peptides and other effectors. Studies have shown that all Drosophila stages can mount effective immune responses, although some of them are stage-specific (for example, the exclusively larval lamellocyte production during encapsulation of parasitoid wasp eggs). Embryos and pupae are interesting models to study wound healing reactions, hemocyte motility and phagocytosis of apoptotic cells (that will not be described here). Humoral and cellular immune responses are usually studied in both larvae and adults. Since the maturation of immune responsiveness is strongly dependent on ecdysone $[9,10]$, immune pathways in the adult stage are less affected by developmental timing. It should be noted that AntiMicrobial Peptides (AMPs) (and many immune genes) show very high levels of inducibility (equivalent to heat-shock genes). Their expression profiles are influenced by multiple parameters and not surprisingly, these genes are picked up in many microarray studies. It is also important to determine whether the observed immune activation has a direct or an indirect cause. For instance, most mutations disrupting the gut compartmentalization lead to higher antimicrobial peptide gene expression in this tissue [11]. This is similar to the observation that many mutations can cause melanotic tumours (cellular like immune response) in a number of indirect ways [12].

Many mutations affect the immune response and in some cases, the differences observed can be down to the genetic background for all the reasons stated above (effect of background on survival for example is illustrated in Fig. 2A). To study subtle immune phenotypes, it is therefore recommended to compare mutants and wild-type in several different background contexts. For instance, use two wild-type stocks such as Canton $^{S}$ and Oregon $^{R}$ and different combinations of mutants (for example mutation over a deficiency, mutant and RNAi).

After raising these points of caution, we describe below some of the methods used in our lab and others to study the immune response to microbes and parasites, with an emphasis on antimicrobial defence mechanisms.

\section{Commonly used pathogens and culture conditions}

Various types of microbes can be used to challenge the Drosophila immune system. Rather than using mammalian pathogens, the organisms of choice are entomopathogenic microorganisms, which naturally infect wild Drosophila populations, and are particularly informative as both parties have evolved attack and survival mechanisms. Among these, genetically tractable organisms in particular have the added value of allowing parallel screening of pathogen virulence genes and host resistance/tolerance genes. Of note, strains from the same bacterial species group can behave differently as virulence factors differ from strain to strain.

\subsection{Bacteria}

Among the large variety of commonly used bacteria, not all are naturally infecting insects. Below we describe two commonly used Gram-negative entomopathogenic bacteria, with further infectious lab strains listed in Table 1. Where available, bacteria carrying fluorescent markers or resistance genes can be used for ease of quantification or re-isolation from the host.

\subsubsection{Gram-negative bacteria}

Pectobacterium (old name Erwinia) carotovora carotovora is a Gram-negative bacterium that causes soft rot in plants and is naturally transmitted by insects. The strain Ecc15 is particularly attractive as it is genetically tractable to some extent, stable, can naturally infect Drosophila, and triggers a very strong immune response while exhibiting a mild lethality in wild-type flies. The use of this strain has been instrumental in studying the systemic immune response as well as the local immune response in trachea or gut and. Ecc15 is grown as a shaking culture in LB medium at $29^{\circ} \mathrm{C}$ and can be reliably identified by its "rotten potato" smell. To infect flies, an overnight culture of $50-100 \mathrm{ml}$ is pelleted by centrifugation ( $15 \mathrm{~min}$ at $3200 \mathrm{~g}$ ) and adjusted to $\mathrm{OD}_{600}=200$. Running plates of Ecc15 can be kept for a month at $4{ }^{\circ} \mathrm{C}$ to start liquid cultures. The Ecc15 wild-type strain carries genomic rifampicin resistance, and a GFP-transformed strain (spectinomycin-selectable) is available for fluorescent tracing of bacteria. Note that the GFP fluorescence contributes slightly to absorbance at $600 \mathrm{~nm}$ and pellet density needs to be adjusted accordingly $[13,14]$.

Another naturally occurring lethal Gram-negative entomopathogen is Pseudomonas entomophila, isolated from a fly in Guadeloupe. P. entomophila is cultured like Ecc15 but is more sensitive to pelleting, because compacted or air-exposed bacteria tend to lyse. This bacterium is genetically unstable and avirulent GacA-like mutants are observed at high frequency. Verifying strains can be done by growing on milk-agar plates to test the proteolytic activity (wildtype but not GacA) [15-17]. A variety of useful P. entomophila mutants have been isolated, including the non-virulent GacA strain, or protease and toxin mutants.

Alternative Gram-negative bacteria are Providencia [18], Serratia marcescens (notably the strain Sm DB11-40, [19]), or Pseudomonas aeruginosa [20,21], which can be found associated with flies in the wild. Laboratory strains of Escherichia coli, although not associated with wild flies, have also been used to probe the immune system, notably the Imd pathway which is activated by DAP-type PGN.

\subsubsection{Gram-positive bacteria}

Gram-positive bacteria can be divided into two types based on their peptidoglycans. Lysine-type peptidoglycan bacteria are strong inducers of the Toll pathway while DAP-type peptidoglycan Gram-positive bacteria including the Bacillus and Listeria genus activate both the Toll and Imd pathways.

Most Lysine-type Gram-positive bacteria are pathogenic to flies upon injection, with the notable exception of Micrococcus luteus that can be used as a non-lethal inducer of the Toll pathway. Enterococcus faecalis and Staphylococcus aureus have been used to probe the Toll pathway in survival experiments, and occasionally Aerococcus viridans has been used to stimulate a Toll-dependent immune response. $S$. aureus is especially interesting to probe the role of phagocytosis and melanization [22,23,131]. Among DAP-type Gram-positive bacteria, Listeria monocytogenes, Listeria innocua, Bacillus megaterium and Bacillus subtilis are currently being used (for example [24]).

Mycobacterium marinum has been used as a Drosophila model for tuberculosis and exhibits the slow killing and wasting characteristics of the disease in humans $[25,26]$.

\subsection{Fungi}

Beauveria bassiana and Metarhizium anisopliae area naturally occurring insect pathogens which infect by breaching the cuticle during sporulation, thanks to a battery of proteo- and lipolytic enzymes. B. bassiana is cultured on malt agar plates at $18-29{ }^{\circ} \mathrm{C}$, in the dark. Higher temperatures result in faster growth rates but may favour contaminating bacteria; to prevent this, plates can be sealed with parafilm. Usually cultures take 1 month to sporulation, which can be induced by switching to $29^{\circ} \mathrm{C}$. It is important to keep 
Table 1

Commonly used pathogens.

\begin{tabular}{|c|c|c|c|}
\hline Bacterium & Gram & Culture conditions & Dose, route and temperature of infection \\
\hline Escherichia coli & Negative, DAP-type & $\mathrm{LB}, 37^{\circ} \mathrm{C}$ & $\mathrm{OD}_{600}=400(\mathrm{~S}), \mathrm{OD}_{600}=200(0), 29^{\circ} \mathrm{C}$ \\
\hline Erwinia carotovora carotovora 15 & Negative, DAP-type & $\mathrm{LB}, 29^{\circ} \mathrm{C}$ & $\mathrm{OD}_{600}=200(\mathrm{~S}), \mathrm{OD}_{600}=100(\mathrm{O}), 25-29^{\circ} \mathrm{C}$ \\
\hline Pseudomonas entomophila & Negative, DAP-type & $\mathrm{LB}, 29^{\circ} \mathrm{C}$ & $\mathrm{OD}_{600}=200(0), 29^{\circ} \mathrm{C}$ \\
\hline Enterobacter cloacae $\beta 12$ & Negative, DAP-type & $\mathrm{LB}, 37^{\circ} \mathrm{C}$ & $\mathrm{OD}_{600}=10(\mathrm{~S}), 22-29^{\circ} \mathrm{C}$ \\
\hline Salmonella typhimurium & Negative, DAP-type & $\mathrm{LB}, 37^{\circ} \mathrm{C}$ & $\mathrm{OD}_{600}=0.1-10(\mathrm{~S}), 22-29^{\circ} \mathrm{C}$ \\
\hline Listeria monocytogenes & Positive, DAP-type & BHI, $37^{\circ} \mathrm{C}$ & $\mathrm{OD}_{600}=0.01-200(\mathrm{~S}), 22-29^{\circ} \mathrm{C}$ \\
\hline Bacillus subtilis & Positive, DAP-type & $\mathrm{LB}, 37^{\circ} \mathrm{C}$ & $\mathrm{OD}_{600}=5-20(\mathrm{~S}), 22-29^{\circ} \mathrm{C}$ \\
\hline Micrococcus luteus & Positive, Lys-type & $\mathrm{LB}, 29^{\circ} \mathrm{C}$ & $\mathrm{OD}_{600}=200(\mathrm{~S}), 29^{\circ} \mathrm{C}$ \\
\hline Staphylococcus aureus & Positive, Lys-type & $\mathrm{LB}, 37^{\circ} \mathrm{C}$ & $\mathrm{OD}_{600}=0.5-200(\mathrm{~S}), 22-29^{\circ} \mathrm{C}$ \\
\hline Staphylococcus saprophyticus & Positive, Lys-type & $\mathrm{LB}, 37^{\circ} \mathrm{C}$ & $\mathrm{OD}_{600}=5(\mathrm{~S}), 22-29^{\circ} \mathrm{C}$ \\
\hline Enterococcus faecalis & Positive, Lys-type & $\mathrm{LB}, 37^{\circ} \mathrm{C}$ & $\mathrm{OD}_{600}=0.01-20(\mathrm{~S}), 22-29^{\circ} \mathrm{C}$ \\
\hline \multicolumn{4}{|l|}{ Fungus, yeast } \\
\hline Candida albicans & & YPG broth, $29^{\circ} \mathrm{C}$ & $\mathrm{OD}_{600}=200(\mathrm{~S}), 22-29^{\circ} \mathrm{C}$ \\
\hline Beauveria bassiana 802 & & Malt agar, $25-29^{\circ} \mathrm{C}$ & Roll flies in sporulating dish, $29^{\circ} \mathrm{C}$ \\
\hline Metarhizium anisopliase KVL 131 & & Malt agar, $25-29{ }^{\circ} \mathrm{C}$ & Roll flies in sporulating dish, $29^{\circ} \mathrm{C}$ \\
\hline Aspergillus fumigatus & & & Spore suspension $(\mathrm{S}), 29^{\circ} \mathrm{C}$ \\
\hline
\end{tabular}

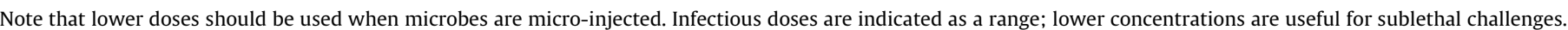
Abbreviations: S, systemic infection; O, oral infection; YPG, yeast peptone glucose; LB, Luria Bertani; BHI, Brain-Heart-Infusion.

plates dry - wipe the lid with clean paper if condensation droplets form. To propagate cultures, flip sporulating plates to new mal agar. Running plates can be kept up to 1.5 months at $18^{\circ} \mathrm{C}$ or until dark spots appear on the fungal lawn.

Other fungi need to be injected to trigger an immune response. Candida albicans is a yeast-like fungus that triggers a strong activation of the Toll pathway. As this fungus exhibits little proteolytic activity, it will elicit a GNPB3-Toll immune response, which has been well characterized [27]. Injection of spores of Aspergillus fumigatus likewise triggers a strong systemic antifungal immune response.

Recently, the immune response to microsporidian species has been addressed [28].

\subsection{Parasites}

In the wild, young Drosophila larvae are often infested by a variety of parasitoid wasps [29]. Some are specific to Drosophila melanogaster (for example Leptopilina boulardi) while others are generalists (for example Leptopilina heterotoma, Asobara tabida), and parasitoid strains differ in their virulence. The more virulent wasps can be propagated in wild-type strains of Drosophila, while less virulent wasps, such as A. tabida, are better cultivated in PPO1, PPO2 double mutants or Drosophila subobscura. Parasitoid wasps will emerge 7-10 days later than flies. The adult parasitoid wasps can be kept on sucrose/agar or honey.

For more information, consult: http://www.jove.com/video/ 3347/an-introduction-to-parasitic-wasps-drosophila-antiparasiteimmune.

Few papers have analyzed the fly response to protozoans (Crithidia, [30]) and nematodes. For nematodes, recently updated methods are available [31-33].

\section{Infectious routes}

Drosophila are naturally exposed to pathogens while foraging on decaying fruit, so the most common route of access is by oral infection to the digestive system or by contact with the tracheal system. However, wild insects also sustain injuries to the cuticle and subsequent introduction of microorganisms into the hemocoel. Sporulating fungi likewise are able to breach the cuticle and extend hyphae into the sterile body cavity. The latter two modes of infection are most easily reproduced in the lab by pricking with a pathogen-contaminated needle.

\subsection{Systemic infection}

To introduce pathogens into the body cavity, anaesthetized adult flies are pricked into the thorax with a thin metal needle dipped in a concentrated bacterial pellet or a suspension of fungal spores (for illustration, see [34]). Pricking into the thorax rather than the abdomen reduces the risk of damaging the intestines, which can easily result in secondary bacteraemia from microbiota. Individuals normally recover quickly after pricking, and the wound site usually displays melanisation within a few hours. To avoid scoring lethally injured individuals, dead flies should be counted at $2 \mathrm{~h}$ after pricking and removed from further analysis.

While needle pricking is a quick and efficient way to deliver a shot of infectious agent, a more precise dosage may be required for certain experiments. For this kind of experiment, it may be useful to microinject a defined volume (nanoliters) of bacterial pellet using a pulled glass capillary mounted on a Nanoject ${ }^{\mathrm{TM}}$ apparatus (for illustrations, see [34]). Capillaries however tend to cause larger wounds, a stronger melanisation reaction and longer recovery times than needles. Alternative methods have been described such as eye injection, genitalia infection $[35,132]$ and placing flies with cut-off legs on contaminated medium. Food vials with freshly injured flies can be kept sideways to prevent weakened individuals from sticking to the medium.

Larval systemic infection is performed with a finer tungsten needle into the posterior lateral side of larvae immobilized on a pre-chilled rubber pad. Larvae can be deposited straight into the bacterial pellet for ease of manipulation. Injured larvae are placed on sealed $5 \mathrm{~cm}$ petri dishes containing apple juice agar or normal fly medium.

After infection, flies or larvae are transferred to the temperature most adapted to optimal pathogen growth (see Table 1).

For infection with fungi, spores can be directly injected as described for bacteria, but for entomopathogenic fungi, the method of choice is to place $\mathrm{CO}_{2}$-anaestethized flies directly on the sporulating fungal lawn and to shake the culture plates until flies are uniformly covered in spores (for illustrations, see [34]). Flies will become gradually infected as spores germinate and breach the cuticle [36]. 


\subsection{Oral infection}

For oral infection, 2-4 day old adults are dehydrated/starved for 2-3 h in empty vials at $29^{\circ} \mathrm{C}$ to ensure synchronous feeding of all individuals when flipped into infection vials. An infection vial consists of standard medium (but without live yeast) completely covered by a Whatman paper disk (Fig. 1A and [15]). The disk is soaked in control solution ( $10 \%$ sucrose) or bacterial pellet mixed with control solution. $120-150 \mu \mathrm{l}$ are sufficient to soak a $22 \mathrm{~mm}$ diameter disk. Starved flies are flipped into the infection vials and kept at optimal temperature for pathogen growth. Experimental evidence suggests that bacteria on the filter disk do not remain viable beyond a couple of hours, therefore it is possible to flip infected flies onto fresh medium after an initial infection phase ( $24 \mathrm{~h}$ for example). Other methods include placing flies on paper towels soaked with bacteria. In this case, fresh bacterial or sucrose solution should be frequently added to avoid dehydration (resulting in continuous infection) [19]. The method of infection (for example with or without prior starvation, continuous or one-shot delivery of bacteria) can have a strong influence on the outcome of the infection.

For natural infection of larvae, individuals are incubated in concentrated solution of bacteria alone or mixed with crushed banana [13]. To prevent larvae from crawling out of the infectious food, transfer them to Eppendorf tubes and plug with a foam stopper. After $30 \mathrm{~min}$, larvae are removed from the mix and transferred to normal food vials. Larvae continue to be infected in the vials. Washing larvae allows stopping the ingestion of bacteria and monitoring persistence. Tracheal infections of larvae are usually carried out at a lower temperature to allow sufficient time, before pupariation, for the development GFP fluorescence from reporter genes. Monitoring the percentage of infected trachea by expression of Drs-GFP is described in Section 4.1.4.

\subsection{Injection of immune elicitors}

Injection of microbes leads to complex immune responses because they involve growth of the microbe within the host. Injection of dead bacteria allows circumventing this problem. To activate a specific branch of the immune response pure elicitors can be used such as TCT (ligand for the Imd activating receptors PGRP-LE and PGRP-LCX/a), DAP-type peptidoglycan (to activate PGRP-LC and PGRP-LE and to a lesser extent PGRP-SA), Lysine-type peptidoglycan (PGRP-SA), $\beta$-glucan (GNBP3), proteases (to activate the psh-Toll pathway). Note that pure LPS has no effect on antimicrobial peptide gene expression but most commercially available LPS preparations (Sigma for example) do show activation of Imd because of trace contaminations by peptidoglycan [37,38]. Pure products can be purchased from InvivoGen or obtained from laboratories specialising in bacterial cell wall biochemistry.

\subsection{Wasp parasitisation}

For wasp infection, 20-30 second instar wild-type larvae are cohoused with 3-4 A. tabida females for $2 \mathrm{~h}$. Parasitized larvae are kept at $\leqslant 25{ }^{\circ} \mathrm{C}$ until capsule dissection 4-6 days post-infection. Lamellocyte differentiation can be visualized by phalloidin staining of hemolymph preparations or with the use of lamellocyte markers.
A

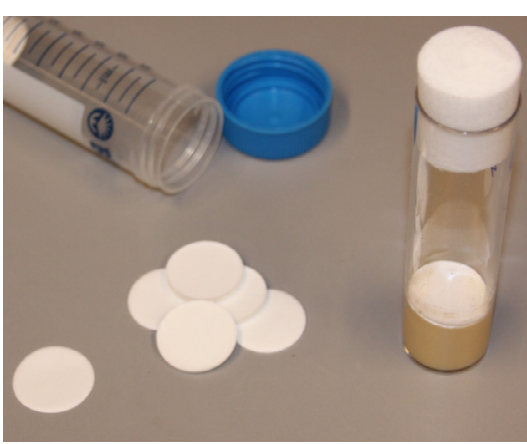

C

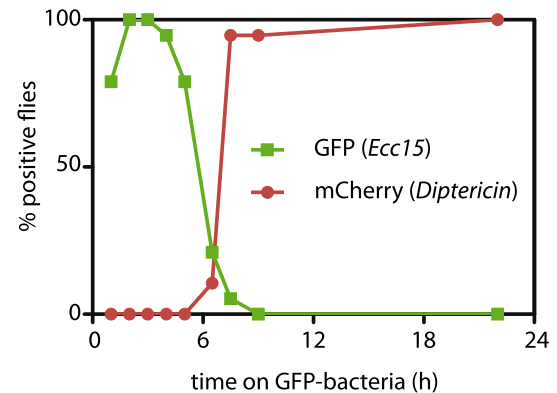

B
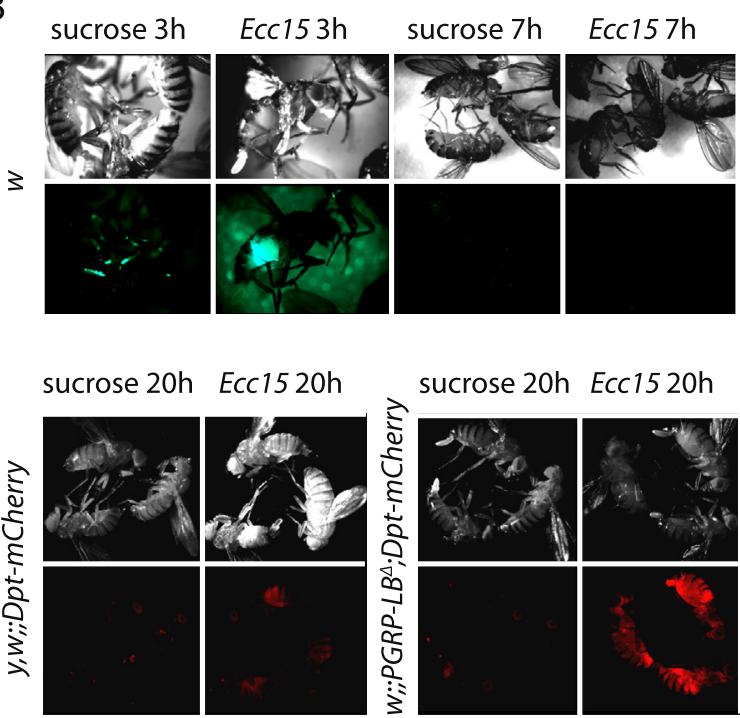

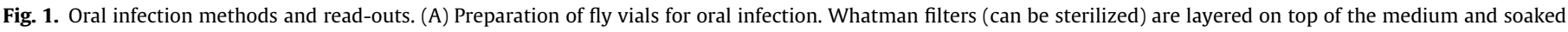

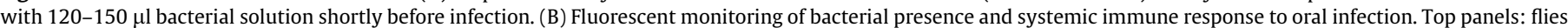

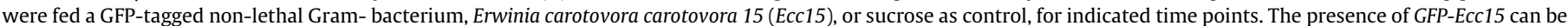

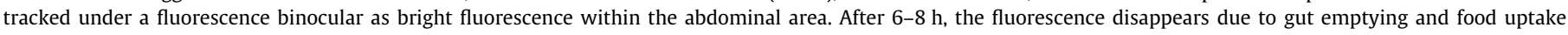

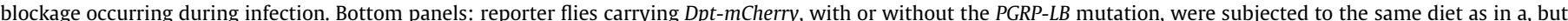

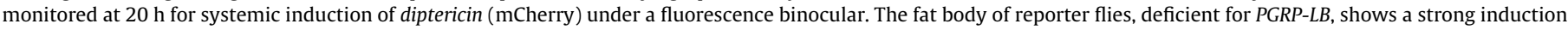
of mCherry [108]. (C) Kinetics for disappearance of bacteria and appearance of immune response signal, derived from observations as in B. 
A

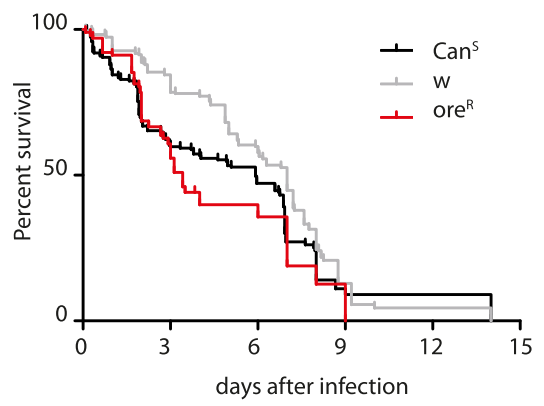

B

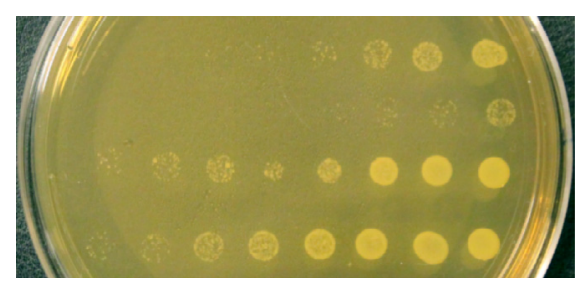

C
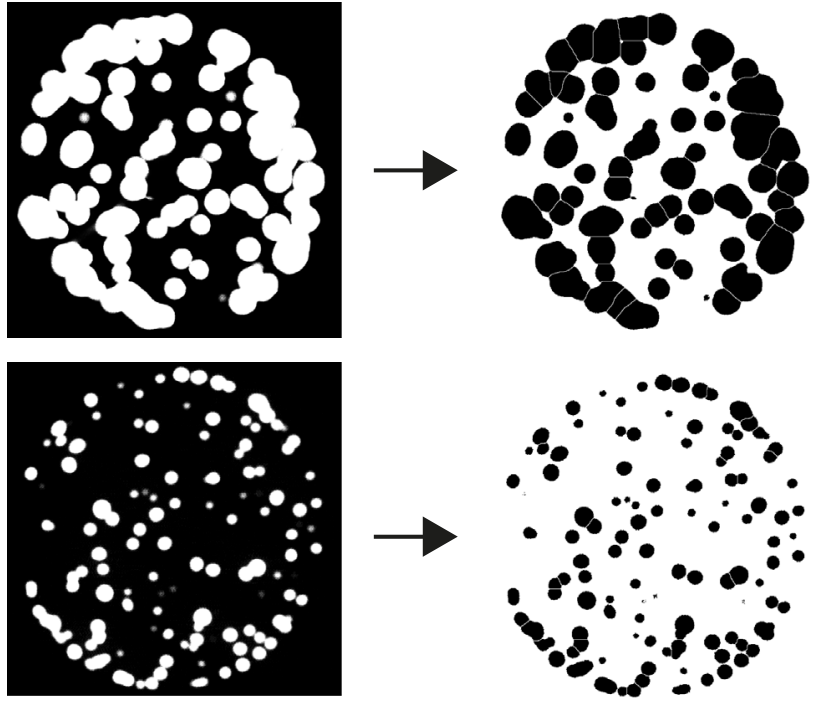

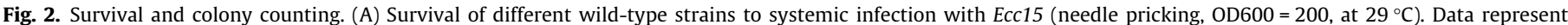

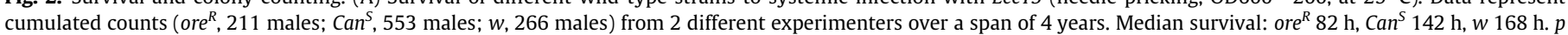

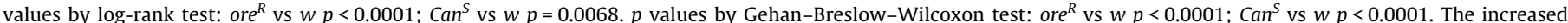

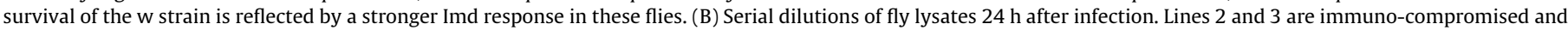

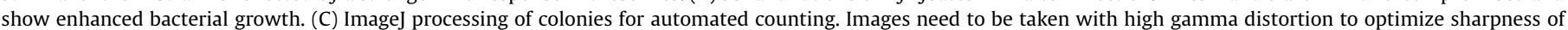

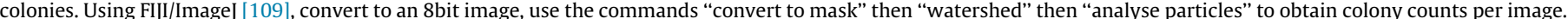

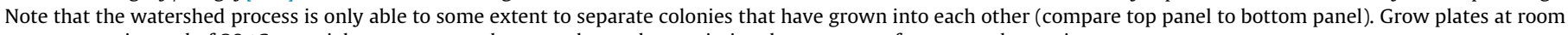
temperature instead of $29^{\circ} \mathrm{C}$ overnight to prevent colony overlap and to optimize the accuracy of automated counting.

\subsection{Germ-free animals}

The Drosophila gut lumen is an environment with relatively low bacterial diversity and numbers (1-30 species, 103-105 CFU/fly). While the number of bacteria is quite consistent at the third larval stage, numbers in adults are extremely variable and the existence of a stable population of dividing bacteria residing in the gut has not yet been formally demonstrated [39-41]. Bacteria found in the Drosophila gut are also found in the substratum, suggesting constant contamination through feeding. Germ-free flies are easily generated by dechorionating embryos with chlorox and then surface-sterilizing them in $70 \%$ ethanol. Sterile dechorionated embryos are transferred to autoclaved fly medium in sterile vials, taking special care not to transfer larvae along with the embryos as their gut contents would re-infect the entire population. Note that germ-free flies will not spontaneously acquire microbiota and need to be placed in the presence of bacteria (derived from other flies or from a culture) to re-acquire their microbiota. Recent papers have added to our understanding of the nature of Drosophila microbiota. Note that germ-free conditions do not only change the gut microbial environment but also the substratum.

The Drosophila symbiont Wolbachia can be removed by treating flies with tetracycline as described in [7].

\section{Methods for scoring the response to infection}

It is becoming increasingly appreciated that immunity to infection does not simply imply getting rid of the causative agent. Homeostasis also requires tissue regeneration and wound healing, 
which rely on stem cell mobilization; rebalancing of energy resources which may have implications on fertility and life span; or possible epigenetic changes which poise the individual against subsequent infections. Below we outline the most commonly used methods and tools to assess outcome of infection, in order to inform such post-infection concepts as resistance, tolerance, resilience, hormesis etc.

\subsection{Commonly used fly stocks}

All flies listed in this publication are publically available through the Bloomington stock centre or will be made available shortly.

\subsubsection{Immune deficiency mutants}

Table 2 lists commonly used immune deficiency mutants. For the Imd pathway, imd ${ }^{1}$ and $\operatorname{Rel}^{\mathrm{E} 20}$ show a complete loss of antimicrobial peptide induction and adults usually die from Gramnegative infection within $24-48 \mathrm{~h}$. For $\operatorname{Re}^{E 20}$, it is advisable to use the cleaned-up background without the ebony marker $[42,43]$. Note that the E20 deletion affects another gene. The Imd ${ }^{1}$ (hypomorph) mutation and null mutations in dTAK1 and PGRP-LC are slightly weaker than null mutations of other members of the pathway (dredd, Ikkß, IKK $\gamma, T a b, d F A D D, I m d)$. The background of the stock influences its overall resistance (see also Fig. 2A) and many mutations are done in the $y, w$ background which shows higher immunoreactivity than for example ore ${ }^{R}$ or $\mathrm{Can}^{S}$. The best way to activate the Imd pathway is to over-express Imd, PGRP-LC, $P G R P-L E$ or the truncated, transcriptionally active form of Relish (Rel68) [44-47].

The Toll pathway has many other non-immune functions and Toll deficient mutants show some zygotic lethality during larval stage with few escapers [48]. Mutations that can be used include $s p z^{r m 7}$ (perfectly viable); a combination of Toll alleles (Tlr632/Tl1$R X A)$, pell74 (a strong hypomorph), and MyD88. The pathway can be activated by over-expression of many genes (for example $s p z$, Pelle, Toll...) or using a gain-of-function mutation in $T l$ (Tl10b or uas-Tl10b) or cactus-deficient flies. Mutations in serine proteases or pattern-recognition receptors upstream of Toll tend to block one of the extracellular branches upstream of SPE and Spz.

Decent RNAi lines for in vivo targeting of the Toll and Imd pathways are also available (for example FADD-IR, Pelle-IR) $[49,50]$.

To target melanisation, several mutants lacking hemolymph PO have been described. The most historic is Black cells, a gain-of function mutation in PPO1 that affects both PPO1 and PPPO2 proteins ([51], Neyen, unpublished observations). More recently, a double PPO1, PPO2 mutant was generated which shows complete absence of PO activity in the hemolymph [131].

Mutants that lack all hemocytes have been described (domino, $L(3) h e m$ ) but they exhibit many other defects as they lack all diploid cells [52]. Viable flies lacking all or most plasmatocytes are called phagoless and can be generated by crossing a hemocyte gal4 driver (Hml-Gal4 or spn-Gal4) to either uas-Bax or both uashid and uas-rpr $[53,54]$.

\subsubsection{Methods for identifying novel immune genes based on large scale} screens and expression profiling

A powerful large-scale tool to identify genes involved in immune activation or regulation is RNA interference (RNAi), either in cell-based screens or in a slightly more laborious in vivo setting [55]. While the patchy efficiency of first generation RNAis relegated in vivo screens to fishing expeditions, improved second-generation RNAi libraries promise optimized throughput in RNAi-based screens. S2-based RNAi screens have successfully identified novel Toll, Imd and JNK pathway components [56-59], determinants of intracellular pathogen resistance [60] or phagocytic receptors on hemocytes [61,62], and in vivo RNAi screens have contributed to our understanding of Drosophila hemocyte development or response to intestinal infection $[63,64]$.

While unbiased reverse genetic screens can be useful to identify novel gene functions, a targeted approach based on contextual gene expression may speed up the process considerably. Microarrays represent a rich source of co-regulated genes in different tissues and infectious conditions, and have been comprehensively reviewed in [65]. The Pathogen Associated Drosophila MicroArray (PADMA) database (www.padmadatabase.org) regroups accessible microarray data sets from a variety of immune challenges [66]. A list of annotated immune genes involved in the Drosophila immune response as well as a collection of microarrays giving transcriptional profiles upon systemic infection, intestinal infection and tracheal infection are available here: http://lemaitrelab.epfl.ch/ resources.

RNAseq datasets represent another avenue to identify novel immune-regulated genes through their association with known immune genes in co-regulated clusters [67]. Finally, the Drosophila Genetic Reference Panel (DGRP) represents a unique asset for population genomics and genome-wide association studies (GWAS) based on 168 fully sequenced strains that can be subjected to any number of infectious challenges [68]. Importantly, polymorphisms associated with changes in immune function coming from this kind of screen will bring to light regulatory, intergenic regions in addition to protein-encoding genes. A first hit with an immune function identified through this GWAS approach is pastrel, a gene that confers allele-specific resistance to common Drosophila viruses [69].

4.1.3. Methods to generate immune deficient cells, tissues or organisms

Many of the classical mutants described in Section 4.1.1 stem from historical EMS (ethyl methanesulfonate) screens. Forward genetic screening based on alkylating agents has the benefit of unbiased targeting of the genome, and can give rise to a variety of mutations from nulls to temperature-sensitive hypomorphs. While mapping EMS mutations can be time-consuming, novel sequencing-based methods have greatly improved efficiency of mapping $[70,71]$. Transposon mutagenesis, albeit suffering from insertion bias [72], allows for easy retrieval of positional information, and forms the basis for a downstream toolkit of genetic applications including imprecise excision knock-out, Gal4-UAS overexpression of flanking genes, or element replacement by targeting vectors, to name but a few [73-77]. Extensive libraries of P-element-based transposon insertions are available through stock centers, along with deletion and duplication lines [78-81]. Finally, targeted gene knock-out using optimized targeting plasmids in combination with CRISPR will greatly accelerate full KO coverage of the fly genome [82].

To address the cell- or tissue-autonomous function of a gene, or to circumvent lethality issues, clonal analysis is a method of choice [83]. While genetic mosaics have been mostly used to delineate neural development pathways, twin-spot and MARCM techniques can be easily adapted to immune tissues [84-87]. Additionally, RNA interference has been widely used to reduce gene expression in a tissue- and time-controlled manner, preventing developmental effects. For more extensive methodology on genome engineering, RNAi screens or navigating large-scale data sets to retrieve gene expression information, the reader is referred to the relevant contributions to this issue.

\subsubsection{Flies carrying reporter constructs}

Large-scale screens require easily scorable read-outs that can be quickly visually inspected. For antimicrobial peptide induction, fluorescent and enzymatic reporter genes are available for both Imd and Toll pathways (Table 2 and Section 4.5, and [34]). 
Table 2

Useful fly strains.

\begin{tabular}{|c|c|c|c|}
\hline Genotype & $\begin{array}{l}\text { Stock } \\
\text { center }\end{array}$ & References & Comments \\
\hline \multicolumn{4}{|l|}{ Antimicrobial peptide gene reporters } \\
\hline$P\{$ Dpt-lacZ, ry+\};;ry & & [110] & $\begin{array}{l}\text { Carries Diptericin-lacZ insertion on } \mathrm{X} \text {. Transgene containing } 2.2 \mathrm{~kb} \text { of the } D p t \text { promoter; provides an } \\
\text { accurate read-out of the Imd pathway in most tissues }\end{array}$ \\
\hline$y, w, P\{$ Dpt-lacZ,ry+\},P\{Drs-GFP, w+ $\}$ & & {$[5,111]$} & $\begin{array}{l}\text { Carries Diptericin-lacZ and Drs-GFP on X. Note that the GFP is secreted (fused after position } 59 \text { of the } \\
\text { Drosomycin } C D S \text { ) }\end{array}$ \\
\hline$w, P\{$ Drs-lacZ, $w+\}$ & & [111] & $\begin{array}{l}\text { Carries Drs-lacZ on X. The Drs-lacZ reporter gene is very strong and shows a significant basal activity } \\
\text { in larvae }\end{array}$ \\
\hline$w ; P\{D p t-G F P, w+\} D 3-2,\{D p t-G F P, w+\} 3-4$ & & [14] & $\begin{array}{l}\text { Carries two recombined copies on each third chromosome (four insertions in total). Useful for } \\
\text { analysis of } D p t \text { expression in barrier epithelia }\end{array}$ \\
\hline$y w ; ; P\{d p t::$ cherry-C1, w+ $\}$ & & [53] & Good reporter of $D p t$ expression \\
\hline$w ; ; P\{$ Dipt-Dpt-HA, $w+\}$ & & [93] & $\begin{array}{l}\text { Carries Dpt promoter followed by Dpt CDS and tag. Reporter of Dpt expression that allows following } \\
\text { the expression of the antibacterial peptide }\end{array}$ \\
\hline \multicolumn{4}{|l|}{ Mutations affecting the Imd pathway } \\
\hline Dipt-lacZ I; b, pr, imd ${ }^{1}$ & & [112] & $\begin{array}{l}\text { Homozygous viable mutation on the second chromosome. } i m d^{1} \text { is a strong hypomorph found in the } \\
\text { old BL1046 Bc stock. Susceptible to Gram-negative bacteria }\end{array}$ \\
\hline$y, w$, Dredd $^{B 118}$ & & {$[43]$} & Null mutation in Dredd. Homozygous viable. \\
\hline$y^{1}, w^{*}, \operatorname{Tak} 1^{2}$ & BL26272 & [113] & Null mutation in dTAK1. Homozygous viable. Susceptible to Gram-negative bacteria \\
\hline$w ; ; P G R P-L C^{E 12}$ & $\begin{array}{l}\text { (see also } \\
\text { BL36323) }\end{array}$ & [45] & Null mutation in the Imd pathway receptor. See also $w * ; P G R P-L C^{45}$ \\
\hline $\operatorname{Relish}^{E 20}, e^{+}$ & & {$[42,43]$} & $\begin{array}{l}\text { A deletion of relish which also affects a nearby gene. The ebony marker of the original stock } \\
\text { (Hultmark lab) was removed by recombination with the Oregon stock. Susceptible to Gram- } \\
\text { negative bacterial infection }\end{array}$ \\
\hline$y^{1}, w^{67 c 23}, P G R P-L E^{112}$ & BL33055 & [114] & $\begin{array}{l}\text { A mutation affecting the pattern-recognition receptor } P G R P-L E \text { that regulates the Imd pathway in } \\
\text { the midgut and in the fat body }\end{array}$ \\
\hline$y^{1}, w^{67 c 23}, P G R P-L E^{112}, P G R P-L C^{E 12}$ & & {$[115]$} & A stock that lacks the two receptors of the Imd pathway \\
\hline dFADD-IR & NIG 12297R-1 & {$[50]$} & This RNAi reduces Imd pathway activity \\
\hline w; UASimd,hspgal4/TM6C & & [50] & $\begin{array}{l}\text { The P[uas-imd, } w+] \text { insertion [44] was recombined with } h s \text {-gal4 allowing activation of the Imd } \\
\text { pathway }\end{array}$ \\
\hline$w ; ; P G R P-L B^{41}$ & & [108] & $\begin{array}{l}\text { A deletion of the negative regulator of the Imd pathway PGRP-LB. PGRP-LB scavenges } \\
\text { peptidoglycan, thereby determining the level of Imd pathway activation. }\end{array}$ \\
\hline$y^{1}, w^{67 c 23} ; P\{E P g y 2\}$ pirk ${ }^{E Y 00723}$ & BL15039 & {$[116-118]$} & A null mutation the negative regulator Pirk \\
\hline $\begin{array}{l}\text { Mutations affecting the Toll pathway } \\
\text { spz }{ }^{\text {rm7} / T M 6 C ~(s e e ~ a l s o ~ s p z ~}{ }^{2} \mathrm{ca}^{1} / \mathrm{TM} 1 \text { ) }\end{array}$ & $\begin{array}{l}\text { (see also } \\
\text { BL3115) }\end{array}$ & & $\begin{array}{l}S p z^{r m 7} \text { is a genetically null, homozygous viable mutation in } s p z \text { generated by EMS. Several markers } \\
\text { of the original stock (M317 Tübingen stock center) including ebony were removed by } \\
\text { recombination }\end{array}$ \\
\hline $\begin{array}{l}T l^{1-R X A}, e / T M 6 C \text { (or any other null allele } \\
\text { of Toll) }\end{array}$ & & & Null mutation in Toll. The TM3SerSB balancer of the original stock was replaced by TM6C \\
\hline $\mathrm{Tl}^{r 632}, \mathrm{ca} / \mathrm{TM} 6 \mathrm{C}\left(\mathrm{Tl}^{r 632}\right.$ was renamed $\left.\mathrm{Tl}^{r 3}\right)$ & BL3238 & & $\begin{array}{l}\text { A thermosensitive mutation in Toll. Tl deficient mutant larvae and adults can be produced by } \\
\text { keeping Tlr632/Tl1-RXA late embryos and young larvae at permissive temperature }\left(18-20^{\circ} \mathrm{C}\right) \text { and } \\
\text { transferring them to restrictive temperature at the pupal stage }\end{array}$ \\
\hline mwh1 e1 $\mathrm{Tl}^{8} / \mathrm{T}(1 ; 3) \mathrm{OR60} / \mathrm{TM} 3, \mathrm{Sb}^{1} \mathrm{Ser}^{1}$ & BL30914 & & $\begin{array}{l}\text { Oregon } 60 \text { is a dominant male lethal mutation. } \mathrm{Tl}^{8}(\mathrm{Tl10b}) \text { is a dominant female sterile mutation } \\
\text { (embryos are ventralized). In this stock all the males are } T l^{8} / T M 3 S e r S b \text {. To obtain } T l^{8} \text { flies, cross these } \\
\text { males with wild-type females. } T l^{8} \text { constitutively activates the Toll pathway inducing a strong } \\
\text { expression of the Drosomycin reporter gene and melanotic tumors }\end{array}$ \\
\hline$P\{$ uas-Tl10b $\}$ & & & Generated by Jean-Marc Reichhart \\
\hline$y, w, D D 1, P G R P-S A^{\text {seml }}$ & & [119] & Homozygous viable mutation in PGRP-SA. Generated by EMS mutagenesis \\
\hline$w ; ; \operatorname{ModSP} P^{1}$ & & {$[24]$} & This null mutation in ModSP blocks the Pattern-recognition branch upstream of the Toll pathway \\
\hline$w ; P[w+$, uas-MODSP $\}$ & & [24] & Over-expression of UAS-ModSP activates the Toll pathway \\
\hline Pelle-IR & NIG 5974R-1 & [49] & $\begin{array}{l}\text { This RNAi stock from the NIG (Mishima) can be used to reduce Toll pathway activity by targeting } \\
\text { the kinase Pelle }\end{array}$ \\
\hline $\operatorname{Re}^{\mathrm{E} 20}, \mathrm{spz^{ \textrm {rm } 7 }}$ & & [120] & $\begin{array}{l}\text { A double mutant lacking Toll and Imd pathway activity (no inducible expression of antimicrobial } \\
\text { peptide gene expression) }\end{array}$ \\
\hline \multicolumn{4}{|c|}{ Mutations affecting melanization and clotting pathways } \\
\hline$P\{$ Dpt-lacZ, ry+ $\} I ; B c / B c$ & BL1036 & {$[51,112]$} & $\begin{array}{l}\text { Dominant mutation affecting an unknown gene located on the second chromosome. } B c /+ \text { larvae } \\
\text { show } 50 \% \text { proPo activity and melanised crystal cells. } B c \text { homozygous larvae show no PO-activity } \\
\text { and melanized crystal cells. This } B c \text { stock derived from the old BL1046 Bc imd }{ }^{1} \text { stock. Another } B c \\
\text { stock is } B c^{1} f j^{1} w t^{1} \text { (BL1036) }\end{array}$ \\
\hline w; spn $27 A^{25 A} /$ Cyo-actin-GFP & & [120] & $\begin{array}{l}\text { Null mutation by P element excision of serpin } 27 A \text {. Spn } 27 A \text { mutants show decreased viability at the } \\
\text { pupal stage. Spn27A larvae and adults show an excessive melanisation reaction after injury }\end{array}$ \\
\hline$w ;$ Spn28D ${ }^{1} /$ CyOGFP II & & [121] & $\begin{array}{l}\text { Deletion of serpin } 28 D \text {. Spn } 28 D \text { mutants show lethality at the pupal stage and excessive } \\
\text { melanization }\end{array}$ \\
\hline$w ; P P O 1\left[w^{+}\right]$ & & [131] & Deletion of PPO1 by homologous recombination (insertion of $\mathrm{w}^{+}$) \\
\hline$w ; P P O 2[w]$ & & [131] & Deletion of $P P O 2$ by imprecise excision \\
\hline$w ; P P O 1, P P O 2\left[w^{+}\right]$ & & [131] & $\begin{array}{l}\text { While mutations in PPO1 reduce melanization, no hemolymphatic melanization is found in PPO1, } \\
\text { PPO2 double mutants }\end{array}$ \\
\hline Hayan $^{1}$ & & [97] & $\begin{array}{l}\text { Null mutation by P element excision of Hayan which encodes the terminal serine protease of the } \\
\text { melanisation cascade. Hayan mutants show a systemic wound response defect and a complete } \\
\text { absence of hemolymph PO activity }\end{array}$ \\
\hline$w^{1118} ;$ PBac $\{W H, \# 3\} H_{m} t^{f 0337} 4$ & BL18646 & [122] & A null mutation in hemolectin. Shows some defect in clotting \\
\hline$w^{1118} ;$ fon $^{424 A} / C y O, P\{$ ActGFP $\} J M R 1$ & BL4344 & [123] & A null mutation in Fondue. Shows some defect in clotting \\
\hline
\end{tabular}


Table 2 (continued)

\begin{tabular}{|c|c|c|c|}
\hline Genotype & $\begin{array}{l}\text { Stock } \\
\text { center }\end{array}$ & References & Comments \\
\hline \multicolumn{4}{|l|}{ Gal4 Drivers (fat body and hemocytes) } \\
\hline$w ; P\{y o l k-G a l 4, w+) / T M 3 S e r$ & & & $\begin{array}{l}\text { The yolk-Gal4 driver strongly expresses Gal } 4 \text { in the adult fat body of females (and also follicle cells } \\
\text { of the ovary). This insertion lowers the viability of flies and as a consequence, yolk-Gal4 stocks are } \\
\text { usually kept at } 23^{\circ} \mathrm{C} \text {. The strength of the driver may be influenced by nutritional state }\end{array}$ \\
\hline$w ; P\{$ GawB $\} c 564$ & BL6982 & & $\begin{array}{l}\text { The c564 driver strongly expresses Gal4 in the adult fat body (and in parts of the gut and } \\
\text { hemocytes) }\end{array}$ \\
\hline$P\{p p l-G A L 4 . P\}$ & & [124] & $\begin{array}{l}\text { The ppl-Gal4 driver strongly expresses Gal4 in the larval and adult fat body (and also in the gut). It is } \\
\text { weaker than c564 at the adult stage }\end{array}$ \\
\hline \multicolumn{4}{|l|}{ Hemocyte drivers and markers } \\
\hline $\begin{array}{l}w^{1118} ; P\{H m l-G A L 4.4\} 2, P\{U A S- \\
\quad 2 x E G F P\} A H 2\end{array}$ & BL30140 & {$[53,54]$} & $\begin{array}{l}\text { This GAL4 line expresses in all the plasmatocytes. Note that this line is deleted for NimC1 gene } \\
\text { [133]. It can be used in combination with uas-Bax or uas-Hid, uas-Rpr to eliminate plasmatocytes }\end{array}$ \\
\hline hemese-Gal4 & & [125] & This GAL4 line expresses brightly in most $(\sim 80 \%)$ of hemocytes \\
\hline w; Srp(hemo)Gal4,UASGFP & & [126] & This GAL4 line expresses dimly in all hemocytes and hemocyte progenitor cells \\
\hline w; pxn-gal4 8.9,uas-GFP & & [127] & This GAL4 line expresses brightly in all plasmatocytes \\
\hline Lz-Gal4;UAS GFP & & [128] & This GAL4 line expresses brightly in all crystal cells \\
\hline $\begin{array}{l}\text { w, Eater-Gal4, UAS-2xEYFP; BcF6-CFP; } \\
\text { MSNF9-mCherry }\end{array}$ & & [129] & $\begin{array}{l}\text { This line labels all three hemocytes types; Eater-Gal4 drives eYFP expression in plasmatocytes, } \\
\text { crystal cells express CFP and lamellocytes express mCherry }\end{array}$ \\
\hline $\begin{array}{l}\text { w; 2x[Hml } \Delta \text {-dsRed.nuc]/SM6a } \\
w ; ; 2 x[H m l \Delta-d s R e d . n u c] / T M 6 c\end{array}$ & & [130] & $\begin{array}{l}\text { These lines carry two independent insertions on Chr II or ChIII and label all plasmatocyte nuclei } \\
\text { dsRed+ }\end{array}$ \\
\hline
\end{tabular}

Many reporter lines (GFP, RFP, LacZ) are available to measure antimicrobial peptide genes. GFP-reporters tend to be slower and not very quantitative compared to lacZ reporters which are very sensitive but stable. Diptericin (Dpt-lacZ, Dpt-GFP, Dpt-mCherry) is the best read-out for the Imd pathway. Toll pathway activity can be monitored by the expression of DIM2 or Drosomycin. One should however bear in mind that Drosomycin induction receives a significant input from the Imd pathway (especially at early time points) and is regulated by the Imd pathway in tracheae. Lines carrying both the Dpt-lacZ and Drs-GFP on the X allow assessing both pathways in a same fly.

A new set of reporter genes have been generated that allow identifying each hemocyte population. Some of these reporter genes mark only differentiated cells while other mark all the lineages (see Table 2).

\subsection{Survival}

Survival to infection is the most holistic approach to assessing defects in immune response. As Drosophilists are not restricted by ethical considerations, sufficiently large numbers of individuals can and should be scored (typically at least 3 biological repeats with cohorts of 30 individuals per genotype and pathogen). Technical issues to consider: if using females, the medium will quickly be worked by hatching larvae and may require more frequent flipping in early stages of an experiment. If using males, the issue of offspring does not arise, but vials containing only males tend to grow sticky with bacteria quicker, and need flipping every 23 days throughout the experiment. Usually infections are done on $\mathrm{CO}_{2}$ anaesthetized flies at room temperature using a cold light. Flies that die within $6 \mathrm{~h}$ are removed from the count and are considered dead by injury.

Depending on the question addressed, infections can be done with lethal or sublethal doses (Table 1). A lethal dose typically should kill all wild-type flies at a constant rate, while a sublethal dose will kill only a fraction of individuals, with the recovered fraction surviving at a plateau before dying from old age or immuno-pathological collateral damage. Statistical considerations: if using a lethal dose, usually the assumption of proportional hazards is true, i.e. death rate for one genotype is constantly proportional to death rate for another genotype, and a direct result of the infection. In this case, the log-rank test is an appropriate and powerful method of analysis, because it gives equal weight to deaths at all the time points. If a sublethal dose was used and death rates taper off after a few days, the assumption of proportional hazards is no longer true, i.e. ratios of deaths per time between groups change with time. In this case, the GehanBreslow-Wilcoxon test, which gives more weight to deaths at early time points, is more appropriate. If survival curves cross, neither test is applicable [88].

It should be noted that survival to a given infectious agent is not comparable between different wild-type backgrounds (Fig. 2A) with differences reaching statistical significance. It goes without saying that correctly matching the wild-type background to analysed genotypes and testing different backgrounds is crucial to survival analysis.

\subsection{Bacterial persistence}

In order to assess the efficiency of an immune response, bacterial clearance can be scored by estimating persistent bacteria within the host. Several more or less quantitative methods are available. First, the presence or absence of fluorescently labelled bacteria can be qualitatively assessed by visual inspection under a fluorescence dissecting microscope. If bacteria are proliferating, systemic infection results in a completely labelled individual. Local retention or proliferation of fluorescently labelled bacteria in the gut can be easily seen through the abdominal cuticle (Fig. 1B). In our hands, GFP-labelled Ecc15 disappears almost completely from infected guts within 6-12 h post-ingestion (Fig. 1B and C).

A second method consists in counting colony-forming units per fly or per tissue at given times after infection. For systemic infection, we usually encounter considerable variability in CFU per fly when flies are infected by needle pricking, because of slight variation in the infectious dose between individuals. This precludes detection of subtle differences in clearance rates between genotypes. A better approach is therefore to inject an exactly reproducible infectious dose by glass capillary and Nanoject ${ }^{\mathrm{TM}}$. To count CFUs, flies are mashed in sterile LB, either manually with a pipette tip or mechanically in a cell lyser and glass-bead filled tubes. The supernatant is then serially diluted in 96-well plates to reach at least 4 sequential countable dilutions when plated. Dilutions are plated on LB-agar with selective antibiotic (if applicable) as $3 \mu \mathrm{l}$ spots, left to dry for a few minutes and incubated until colonies are visible (Fig. 2B). A quick and reliable way of counting colonies is by automated image analysis (Fig. 2C). 
For oral infection, an obstacle to accurate quantification is microbial contamination on the fly's appendages. To eliminate surface bacteria as much as possible, individuals are dipped in $70 \%$ ethanol $5 \mathrm{~s}$, then rinsed in sterile water or PBS and dried by touching a tissue paper before collecting. This method however has limitations, because not all flies may be surface-sterilized, and because ethanol can flood the extremities of the digestive tract and kill bacteria in the crop or anal pouch.

A third method is PCR-based quantification of bacterial genes on fly extracts (see [89] for Spiroplasma and [26] for M. marinum).

\subsection{Transcriptional activation, mRNA quantification}

A straightforward way of assessing expression of genes independently of reporter engineering is quantitative real-time PCR. Technicalities to consider include numbers of individuals and tissues (as an indication: 10 adults or 15 larvae or 15 fat bodies or 20 intestines), extraction (TriZol and isopropanol precipitation or spin columns), RNA treatment (DNase digestion or not), kinetics of gene expression, target and reference genes. It can also be useful to normalize gene induction to a known entity, for example maximal induction in a given wild-type strain, in order to make sense of "fold changes" upon a test treatment. A selection of reporter genes is listed in Table 3.

Some general considerations on gene expression may be worthwhile pointing out: although immune gene induction is normally robust, many genes display circadian rhythmicity, and measurements might be improved by consistent fly husbandry ( $12 \mathrm{~h}$ light/dark cycle, controlled temperature) [90,91]. NF- $\kappa B$ signalling (Toll/Imd) in particular is oscillatory in nature and kinetics rather than single time points may be more informative for a complete picture of immune homeostasis [92].

While mRNA quantification gives a fairly accurate picture of which genes are switched on, it does not inform on the actual efficiency of the gene products. Indeed, recent publications from different areas of infection biology suggest that translation can be inhibited during infection. Ideally, where antibodies or tagged gene products are available (for example the Dipt-Dpt-HA construct described in [93]), protein expression should be assessed in parallel to see whether the kinetics of mRNA induction are matched by the kinetics of effector production (protein or enzymatic product).

\subsection{Reporter lines}

Reporter constructs which combine immune-inducible promoters with reporter enzymes or fluorescent proteins provide an alternative approach to study gene expression in a spatiotemporal manner. LacZ and GFP enhancer traps are riddling the genome; alternatively, Gal4 traps can be coupled to UAS-reporters of choice to assess gene induction [94]. Below we outline immune-specific reporter strains (listed in Table 2) and how to use them for immune gene quantification.

\subsubsection{Non-fluorescent markers of immune activation}

A historical way of scoring gene expression is by enzymatic titration of a reporter enzyme (peroxidase, $\beta$-galactosidase) driven by the promoter of the gene of interest. P[lac-Z] insertion strains are available from stock centres for a vast number of genes, see also Table 2 for a selection of immune gene-lacZ reporters.

To analyse gene expression by X-gal staining and subsequent microscopic observation, tissues of interest from P[lac-Z]-expressing larvae or adults are dissected in PBS at $4{ }^{\circ} \mathrm{C}$ and fixed in PBS with $0.5-1 \%$ glutaraldehyde at $4{ }^{\circ} \mathrm{C}$. Length of fixation depends on thickness of tissue (seconds for hemocytes, minutes for intestines or fat bodies).

For X-gal staining the following reagents are used: X-gal (5-bromo-4-chloro-3-indolyl $\beta$-D-galactoside) prepared as a $5 \%$ solution in dimethylformamide and stored at $-20^{\circ} \mathrm{C}$; staining buffer composed of $10 \mathrm{mM} \mathrm{NaH} \mathrm{PO}_{4} / \mathrm{Na}_{2} \mathrm{HPO}_{4}, 150 \mathrm{mM} \mathrm{NaCl}, 1 \mathrm{mM}$ $\mathrm{MgCl}_{2}, 3.5 \mathrm{mM} \mathrm{K}_{3} \mathrm{FeCN}_{6}, 3.5 \mathrm{mM} \mathrm{K}_{4} \mathrm{FeCN}_{6}$ and adjusted to $\mathrm{pH} 7.2$ with $\mathrm{NaOH}$. X-gal stock should be added to the staining buffer shortly before use, at $30 \mu \mathrm{l} / \mathrm{ml}$ buffer. After washing the fixed tissues in PBS (1-3 times depending on thickness), incubate in staining buffer with X-gal at $37^{\circ} \mathrm{C}$ or at RT. The length of incubation depends on the amount of expressed enzyme (from minutes to overnight). Particular attention should be focused on experimental $\mathrm{pH}$ : constitutively expressed $\beta$-galactosidase (midgut) is active at $\mathrm{pH}$ 6.5, while P[lac-Z]-derived $\beta$-galactosidase has an optimum at $\mathrm{pH} 7.5$.

To quantify gene expression by $\beta$-galactosidase activity titration, whole animals (3-5 individuals per genotype) or dissected tissues (15-20 intestines, 10-15 carcasses) are collected and lysed in glass-bead filled screw-cap tubes in buffer $\mathrm{Z}\left(60 \mathrm{mM} \mathrm{Na}_{2} \mathrm{HPO}_{4}\right.$, $60 \mathrm{mM} \mathrm{NaH} \mathrm{PO}_{4}, 10 \mathrm{mM} \mathrm{KCl}, 1 \mathrm{mM} \mathrm{MgSO}$, $50 \mathrm{mM} \beta$-mercaptoethanol, adjusted $\mathrm{pH}$ to 8 with $\mathrm{NaOH}$ ). All steps are carried out

Table 3

Primer list.

\begin{tabular}{|c|c|c|c|c|}
\hline FlyBase & Name & Symbol & Forward & Reverse \\
\hline CG7939 & Ribosomal protein L32 & RpL32 & GACGCTTCAAGGGACAGTATCTG & AAACGCGGTTCTGCATGAG \\
\hline CG8175 & Metchnikowin & Mtk & AACTTAATCTTGGAGCGA & CGGTCTTGGTTGGTTAG \\
\hline CG1385 & Defensin & Def & GTTCTTCGTTCTCGTGG & CTTTGAACCCCTTGGC \\
\hline CG10146 & Attacin-A & AttA & CCCGGAGTGAAGGATG & GTTGCTGTGCGTCAAG \\
\hline CG10816 & Drosocin & Dro & CCATCGTTTTCCTGCT & CTTGAGTCAGGTGATCC \\
\hline CG1365 & Cecropin A1 & CecA1 & GAACTTCTACAACATCTTCGT & TCCCAGTCCCTGGATT \\
\hline CG12763 & Diptericin & Dpt & GCTGCGCAATCGCTTCTACT & TGGTGGAGTGGGCTTCATG \\
\hline CG14704 & Peptidoglycan recognition protein LB & PGRP-LB & CTTGTTTGTTTGTTTATTTTTGTG & CGGTAACCGTCGAGGC \\
\hline CG11992 & Relish & Rel & ACAGGACCGCATATCG & GTGGGGTATTTCCGGC \\
\hline CG15154 & Suppressor of cytokine signaling at $36 \mathrm{E}$ & Socs36E & GCACAGAAGGCAGACC & ACGTAGGAGACCCGTAT \\
\hline CG5963 & unpaired 3 & upd3 & GCGGGGAGGATGTACC & GTCTTCATGGAATGAGCC \\
\hline CG7850 & puckered & puc & TGGCTCTGTTCAAGCG & CCTTATCTCAGTCCCTCG \\
\hline CG3131 & Dual oxidase & Duox & TAGCAAGCCGGTGTCGCAATCAAT & ACGGCCAGAGCACTTGCACATAG \\
\hline CG31508 & Turandot C & TotC & TGGGCTATTCTGACGAGG & TCCGACGTACTTGGTCT \\
\hline CG14027 & Turandot M & TotM & CGGAACATCGACAGCC & CGCTTGACTCCCTCAGA \\
\hline CG10810 & Drosomycin & Drs & CGTGAGAACCTTTTCCAATATGATG & TCCCAGGACCACCAGCAT \\
\hline CG32283 & Drosomycin-like 3 & Drsl3 & CAGATGATATTCCTGTTTGCT & TGTCCСTCCTCAATGC \\
\hline CG16844 & Immune induced molecule 3 & IM3 & CGGGAGTCAAGCTCAGA & GTGGCTGTGTGAACTTCAA \\
\hline CG6134 & spätzle & spz & GATCTTCAGCCCACGG & CGAAGTCACAGGGTTG \\
\hline CG5490 & Toll & $\mathrm{Tl}$ & AGAGCGACGTATAGGACT & ACCTATAAGAGGGCGACT \\
\hline
\end{tabular}


on ice. Debris-free supernatants are collected by centrifugation and immediately processed as melanization interferes with the assay. Quantification is done in a 96-well format; samples and control buffer are distributed at $5 \mu \mathrm{l} /$ well, then $200-250 \mu \mathrm{l}$ buffer $\mathrm{Z}$ with $0.35 \mathrm{mg} / \mathrm{ml}$ ortho-Nitrophenyl- $\beta$-galactoside (ONPG) is added. Plates are then incubated in a heated microplate reader $\left(37^{\circ} \mathrm{C}\right)$ and measurements taken every $5-10 \mathrm{~min}$ at $420 \mathrm{~nm}$. Usually a half-hour time-course is sufficient to obtain accurate quantification; it is advisable to pre-warm the plate for up to $30 \mathrm{~min}$ at $37^{\circ} \mathrm{C}$ as accumulation of the colour reagent may remain undetectable at first (check for appearance of faint yellow colour in positive samples). In parallel, set up a 96-well format protein quantification (Bradford or BCA) using the same sample volume $(5 \mu \mathrm{l})$.

$\beta$-Galactosidase activity is expressed as $\frac{\Delta \mathrm{OD} 420 / \Delta t(\min )}{\text { protein concentration } \times 0.0045}$ (in enzymatic units per amount of protein).

\subsubsection{Fluorescent markers of immune activation}

Similarly to lac-Z reporter genes described for enzymatic quantification, gene expression can also be assessed using fluorescent reporter strains, listed in Table 2.

If a simple off/on answer is sufficient, flies can be inspected simply by eye on a fluorescent stereomicroscope. Systemic and localized immune activation is easily scorable from $4 \mathrm{~h}$ onwards using GFP or mCherry fluorescence in whole animals, as illustrated in Fig. 1B and C. Microscopic analysis of live or fixed and stained immune responsive tissues (for example, hemocytes, tracheae, intestines, fat body) can give a more detailed insight into whether the response is restricted to specific cells within a tissue. This is particularly informative when analysing mosaics as it allows comparing immune activation of wild-type versus $\mathrm{KO}$ cells in a same tissue exposed to identical levels of infection.

\subsection{Melanisation read-outs}

Melanisation takes place in the hemolymph compartment and results in the synthesis of an insoluble black pigment called melanin as well as oxidative by-products, which are bactericidal $[95,96]$. During the melanisation reaction, sequential enzymatic cleavage of secreted serine proteases results in the cleavage of the pro-phenoloxidase PPO into its enzymatically active form PO. Once activated PO catalyses the oxidation of phenols into quinones which subsequently polymerize into melanin. The section below describes the most common assays used to monitor PO.

\subsubsection{Collection of hemolymph}

Collection of cell-free hemolymph is the first step to any experiments attempting to quantify PO activity. Since pro-phenoloxidases are secreted by crystal cells (see Section 4.6.5), a cell type highly sensitive to mechanical disruption, great care must be taken to avoid collecting cells along with the hemolymph.

The easiest and most efficient way of collection is by gentle centrifugation of intact larvae. 15-20 individuals are placed on a $10 \mu \mathrm{M}$ filter spin column, covered with $4 \mathrm{~mm}$ glass beads and centrifuged for $20 \mathrm{~min}$ at $4{ }^{\circ} \mathrm{C}, 10 \mathrm{~K} \mathrm{rpm}$ in a microcentrifuge. The weight of the beads is generally sufficient to extract hemolymph during the run, but animals can be pricked with a needle prior to centrifugation in order to optimize recovery. The filter column ensures that most cell debris is retained during centrifugation.

A more accurate but also more time-consuming method is hemolymph collection with a pulled glass capillary mounted on a Nanoject ${ }^{\mathrm{TM}}$ apparatus.

Independently of collection technique, the resulting hemolymph samples need to be kept on ice throughout the collection process and supplied with a concentrated protease inhibitor solution (for example Roche cOmplete ${ }^{\mathrm{TM}}$ Protease Inhibitor Cocktail
Tablets) to avoid any spontaneous proteolytic activation of PO. Hemolymph protein concentration can be determined by any conventional protein quantification method.

Ideal collection times after wounding are $30 \mathrm{~min}$ for larvae and $4 \mathrm{~h}$ for adults.

\subsubsection{DOPA assay}

The DOPA test is a quantitative colorimetric assay frequently used to monitor PO activity of hemolymph samples. The assay is based on the conversion by PO of the substrate L-DOPA (L-3,4-dihydroxyphenylalanine) into a red pigment called dopachrome and the measurement of its absorbance at $492 \mathrm{~nm}$. Coloration intensity is dependent on the initial amount of activated PO in the reaction.

In detail, spectrophotometer cuvettes are filled with 5-25 $\mu \mathrm{g}$ of hemolymph protein in a total volume of $200 \mu \mathrm{l} 5 \mathrm{mM} \mathrm{CaCl} 2$ solution (containing protease inhibitors, see Section 4.6.1). After addition of $800 \mu \mathrm{l}$-DOPA solution ( $20 \mathrm{mM}$ in phosphate buffer adjusted to $\mathrm{pH} 6.6$, freshly prepared and protected from light) samples are incubated at $29^{\circ} \mathrm{C}$ in the dark. After $30 \mathrm{~min}$ the optical density at $492 \mathrm{~nm}$ is measured for each sample (a microplate reader can also be used in case of numerous samples) against an L-DOPA control containing no hemolymph.

Note that because proteases inhibitors were added immediately after hemolymph collection, the values reflect the actual in vivo PO activity at the time of collection. To measure total PO and PPO activities, protease inhibitors should be replaced by chymotrypsin which facilitates the cleavage of PPO into PO. Black cells $(B C)$ and $\mathrm{PPO}^{\Delta}{ }^{\Delta}, \mathrm{PPO}^{\Delta}$ mutant flies that lack hemolymph PO activity can be used a negative control for the reaction (see Table 2 for PO-deficient mutants).

\subsubsection{PPO cleavage assay}

As a complement to the PO assay, a Western Blot using antibodies against Drosophila PO1 and PO2 can be performed on larval or adult hemolymph samples $[97,131]$. By this method, both the naïve PPO (75 kDa) and the mature form of PO (70 kDa), resulting from PO activation upon proteolytic cleavage by the upstream serine protease Hayan, can be detected. To enhance the efficiency of PO cleavage, flies can be infected with a mixture of Gram-positive and Gram-negative bacteria.

\subsubsection{Optical read-outs}

A very easy but non-quantitative way to monitor the melanisation reaction in adults consists in pricking flies in the thorax with a needle as for systemic infections. The blackening of the wounded area due to melanin deposition can be observed already $30 \mathrm{~min}$ post injury (Fig. 3). To image the size and the intensity of the melanisation on the wounded thorax, pictures can be taken using a camera attached to a microscope 4 hours post wounding. Note that the wounding reaction differs according to the bacterial strains; $L$. monocytogenesis and $S$. aureus tend to induce larger melanization spots [98].

In larvae, the melanisation reaction can be observed in larvae after pricking with a thin needle usually on posterior side [34]. 5 min after injury, synthesis of melanin on the surface of the cuticle is already visible. Pictures of the melanisation can be taken $30 \mathrm{~min}$ post injury. It is important to keep in mind that the melanisation reaction can vary considerably between animals. In order to have a clear representation of the melanisation reaction in wounded specimen it is essential to repeat the experiment several times and to take a large number of pictures that illustrates the melanised area. Spn27A ${ }^{1}$ flies lacking the serpin Spn27A negative regulator show a precocious and uncontrolled melanisation reaction even in absence of injury. $P P O 1^{\Delta}, P P O 2^{\Delta}$ or $B C$ mutant flies that lack hemolymph PO activity can be used as a negative control of the reaction (see Table 2 ). 

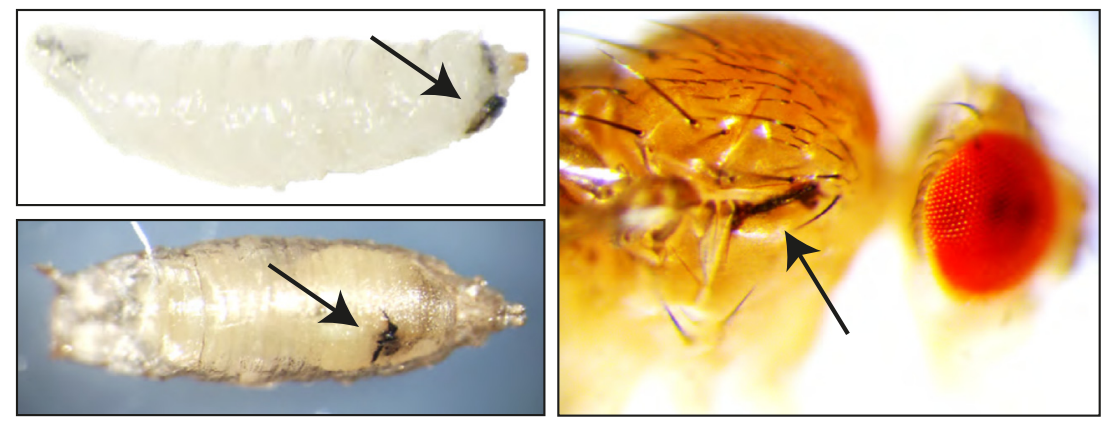

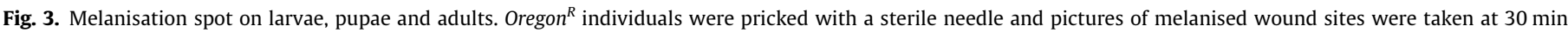
(larvae) or $3 \mathrm{~h}$ (pupae and adults) after injury.

\subsubsection{Crystal cell visualisation}

Crystal cells are specialised larval hemocytes responsible for the synthesis and the release of PPOs. In larvae, crystal cells can be visualized using a transgenic strain carrying lz-Gal4, UAS-GFP which expresses GFP under the control of the crystal cell-specific promoter lozenge (see Table 2). Alternatively, spontaneous activation of PPO in crystal cells can be achieved by incubating larvae in PBS at $65^{\circ} \mathrm{C}$ for $10 \mathrm{~min}$ [99].

\subsection{Oxidative burst}

Several ROS quantification methods have been developed over recent years. Here we limit ourselves to ROS detection in the gut. Here we describe one of the more commonly used probes, i.e. $2^{\prime}, 7^{\prime}$-dichlorofluorescein-diacetate (DCFH-DA) that is used to sense specifically $\mathrm{H}_{2} \mathrm{O}_{2}[93,100]$. We measured ROS levels in the adult gut of female flies by the addition of $100 \mu \mathrm{M}$ DCFH-DA fluorescent dye (Sigma) to freshly dissected gut tissue. The dissections are done in the presence of $20 \mathrm{mM}$ NEM (N-ethyl maleimide, Sigma) and the tissue is preserved in NEM until addition of DCFH-DA dye. The tissue is then incubated in the dye for $30 \mathrm{~min}$ and then mounted in $70 \%$ Glycerol. Sections of anterior midguts should be imaged. The DCFH-DA fluorescent signal is analysed using excitation at $488 \mathrm{~nm}$ and emission at $529 \mathrm{~nm}$. An important consideration is growing flies without live yeast as this may influence basal levels of ROS in the intestine. For the quantification we use pixel values of signal intensity and take the average signal measured on representative fields of at least 6 guts.

Recently, the group of Won-Jae Lee has employed a novel probe for measuring ROS in Drosophila intestine [101]. This probe (R19S) is a rhodamine-based sensor which specifically reacts with $\mathrm{HOCl}$ and not with other ROS [102]. In the same publication, the group utilized $100 \mathrm{mM}$ of Amplex UltraRed reagent (Invitrogen) and $0.2 \mathrm{U} / \mathrm{ml}$ of horseradish peroxidase (Sigma) reaction buffer to measure $\mathrm{H}_{2} \mathrm{O}_{2}$ in Caenorhabditis elegans. The probe DCFH-DA and Amplex UltraRed reagent have been used previously for fluorescencebased quantitative measurements in human cell culture. For Drosophila a similar quantitative measurement has yet to be reported.

For protocols on how to measure oxidative burst by fluorimetric indicators coupled to immunohistochemistry, the reader is referred to the excellent methods developed by the Banerjee lab (http://www.nature.com/protocolexchange/protocols/414).

\subsection{Hemocyte observation}

Basic protocols to observe hemocytes were described in [34].

\subsection{Phagocytosis assays}

The phagocytosis assay described below has been optimised in our lab from a combination of similar methods [23,103,104]. In this protocol, larval hemocytes are collected and mixed with fluorescent heat-killed bacteria, incubated and then run on a flow cytometer to measure the fraction of cells phagocytosing and the intensity of phagocytic uptake. Phagocytosis can be reduced by injecting beads in the body cavities [105]. Recently, assays to monitor phagosome maturation have been developed [106].

To assay phagocytosis, 2-5 day old 30 female and 15 male flies are grown in large vials ready-sprinkled with yeast and containing $10 \mathrm{~mL} 0.05 \%(\mathrm{w} / \mathrm{v})$ bromophenol blue fly food at $25^{\circ} \mathrm{C}$. Cultures are flipped every morning $(24 \mathrm{~h})$ to yield a rearing density of 100 150 eggs per vial. Collect an excess of wandering L3 larvae with light blue to white guts. Before dissection, larvae are washed in $\mathrm{H}_{2} \mathrm{O}$ to remove food, and re-suspended in PBS but not totally submerged such that they remain oxygenated. Prior to bleeding, larvae are dried on precision tissues (Kimtech, Kimberly-Clark).

The number of larvae to bleed depends on genotype (see below). Bleeds are collected in $120 \mu \mathrm{l}$ cold Schneider's medium (Gibco) containing $1 \mathrm{nM}$ phenylthiourea (PTU, Sigma, freshly prepared) bounded by a hydrophobic ring, drawn using an ImmuEdge pen (Vector Laboratories Inc., US) on a glass slide. The glass slide is atop a $9 \mathrm{~cm}$ petri plate filled with ice, used to chill the larvae.

To bleed, chilled larvae are dissected by holding the posterior with $45^{\circ}$-angled tweezers (Inox, No. 5) and with second pair, pinching posterior cuticle and pulling anteriorly to release hemocytes into the medium. A $100 \mu \mathrm{l}$ volume of cells is transferred to an ultra-low attachment 96-well plate (Corning, Costar no. 3474) and incubated at RT for $10 \mathrm{~min}$. The bacteria are then added: $2 \times 10^{6}, 2 \times 10^{7}$ or $2 \times 10^{8}$ Alexa-Fluor 488 heat-killed $E$. coli or S. aureus (Molecular Probes, for preparation see Section 5.8 .3 below) in $10 \mu \mathrm{l}$ Schneider's/PTU to each well. The bacteria and hemocytes are mixed by gentle pipetting 7 times. The cells are incubated at RT for $20 \mathrm{~min}$ to enable phagocytosis. Immediately afterwards, $50 \mu \mathrm{l} 0.4 \%$ Trypan blue (Sigma, store at RT) is added to quench the fluorescence of extracellular bioparticles. Trypan blue should be pre-spun, $10 \mathrm{~min}, 13,000 \mathrm{rpm}$ to pellet insoluble particles and kept at RT to avoid precipitation. Immediately run the quenched sample on a flow cytometer (BD Accuri, US) and measure the mean fluorescence intensity of the single cell population relative to a non-fluorescent control (no bacteria added).

\subsubsection{Calculation of phagocytic index}

$\%$ of Cells phagocytosing $=100 \times$ [number of singlets in fluorescence positive gate]/[number of singlets in fluorescence negative gate].

Phagocytic index, PI = [mean fluorescence intensity of singlet population in bacteria-added sample]/[mean fluorescence intensity of non-fluorescent, no bacteria added, control].

Typical flow cytometry measurements of hemocyte phagocytosis of AF488-labelled heat killed S. aureus and a calculation of the phagocytic index are shown in Fig. 4. 
$(-)$

AF488-S. aureus

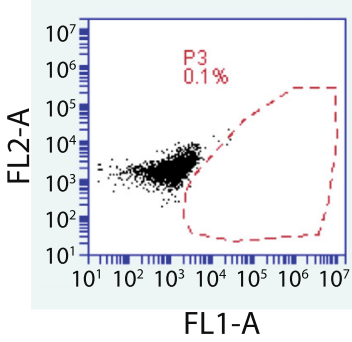

$\langle\mathrm{FL} 1-\mathrm{A}\rangle_{\mathrm{c}}=1385$

$\mathrm{PI}=\frac{\langle\mathrm{FL} 1-\mathrm{A}\rangle_{\mathrm{AF} 488}}{\langle\mathrm{FL} 1-\mathrm{A}\rangle_{\mathrm{C}}}$
(+) $2 \times 10^{6}$

AF488-S. aureus

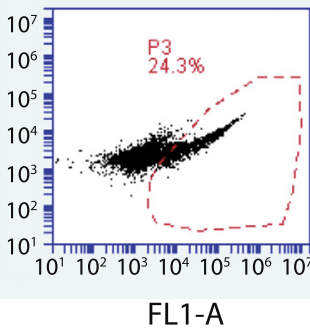

$\langle\mathrm{FL} 1-\mathrm{A}\rangle_{\mathrm{AF} 488}=16309$

$\mathrm{PI}=11.8$
(+) $2 \times 10^{7}$

AF488-S. aureus

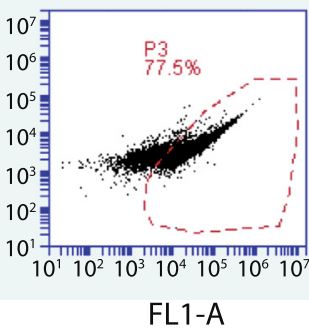

$<\mathrm{FL} 1-\mathrm{A}\rangle_{\mathrm{AF} 488}=45437$

$\mathrm{PI}=32.8$
(+) $2 \times 10^{8}$

AF488-S. aureus

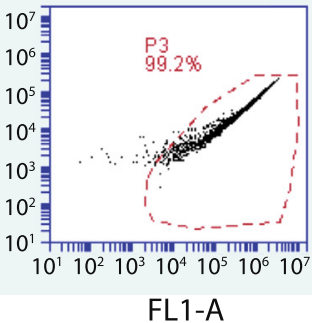

$<\mathrm{FL} 1-\mathrm{A}\rangle_{\mathrm{AF} 488}=805446$

$\mathrm{PI}=581.5$

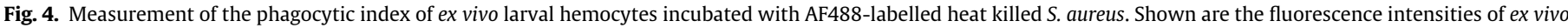

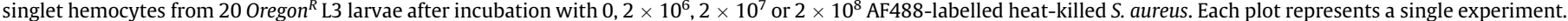

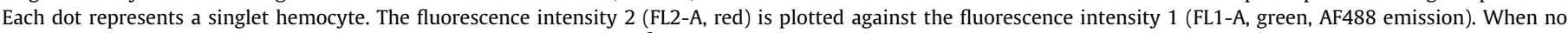

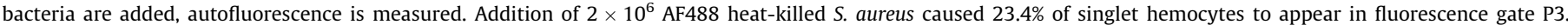

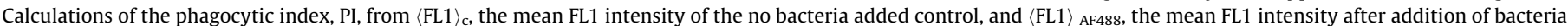
are shown directly below each plot. After addition of $2 \times 10^{8}$ AF488-S. aureus, phagocytosis was around 50 times higher than after addition of $2 \times 10^{6}$ AF488-S. aureus.

\subsubsection{Hemocyte numbers}

Circulating hemocyte number in third instar larvae varies between genotypes, therefore, to achieve cell-matched assays across genotypes, it is necessary to adjust the number of larval bleeds between genotypes. On average, 20 larval bleeds from Oregon $^{R}$ yields $\sim 5000$ singlet hemocytes and $w^{1118}$ (BL5905) yields $\sim 7500$ singlet hemocytes using the above protocol. Therefore, before doing phagocytosis assays, use the flow cytometer to measure the hemocyte yield per 20 larval bleeds for each genotype and compare to wild type $\operatorname{Oregon}^{R}$. Then use hemocyte yield-adjusted numbers of larval bleeds to achieve 20 Oregon $^{R}$ larval bleed equivalents or $\sim 5000$ singlet hemocytes for all assays across all genotypes.

\subsubsection{Preparation of bioparticles}

To prepare fluorescent heat-killed Alexa-Fluor conjugated E. coli or S. aureus (Molecular Probes), $2 \mathrm{mg}$ lyophilized bacteria are dissolved in $2 \mathrm{~mL}$ sterile PBS and vortexed for $1 \mathrm{~min}$ at top speed. The bacterial particles suspension is further homogenised by passaging 40 times through a $25 \mathrm{G} \times 1.5^{\prime \prime}$ hypodermic needle (Sterican, Braun) mounted on a $2 \mathrm{~mL}$ syringe. To determine particle number, dilute a sample serially 10 -fold to $1 / 1000$ in PBS, $0.05 \%$ Tween-20 and count using a hemocytometer, $\times 40$ objective. Typically $1.0-6.0 \times 10^{10}$ particles are present per $\mathrm{mL}$. Keep on ice and make $10 \mu \mathrm{l}$ aliquots, freeze overnight at $-80^{\circ} \mathrm{C}$ and store at $-20^{\circ} \mathrm{C}$. While aliquoting, it is extremely important to vortex the bacterial suspension for $5 \mathrm{~s}$ between aliquots.

Before use in a phagocytosis assay, aliquots are diluted to the desired concentration and vortexed for $30 \mathrm{~s}$ after preparation and for $15 \mathrm{~s}$ before each use.

\subsection{Clotting assay}

Several protocols have been developed to monitor clotting in third instar larvae. This includes various histological methods to visualize the clot, bead aggregation assays, draw out techniques to monitor the viscosity of hemolymph. For details see [107] as well as a movie of a drawout of a hemolymph sample from fondue mutant larvae http://booksite.elsevier.com/9780123739766/.

\section{References}

[1] K.A. McKean et al., BMC Evol. Biol. 8 (2008) 76

[2] S.M. Short, B.P. Lazzaro, G3 (Bethesda) 3 (5) (2013) 827-840.

[3] N. Buchon, N.A. Broderick, B. Lemaitre, Nat. Rev. Microbiol. 11 (9) (2013) 615 626.

[4] D. Ferrandon, Curr. Opin. Immunol. 25 (1) (2013) 59-70.

[5] D. Ferrandon et al., EMBO J. 17 (5) (1998) 1217-1227.

[6] J.A. Chandler, P.M. James, PLoS One 8 (4) (2013) e61937.

[7] E. Chrostek et al., PLoS Genet. 9 (12) (2013) e1003896.

[8] J. Xie et al., Heredity (Edinb) (2013).

[9] J.C. Regan et al., PLoS Pathog. 9 (10) (2013) e1003720.

[10] F. Rus et al., EMBO J. 32 (11) (2013) 1626-1638.

[11] N. Buchon et al., Cell Rep. 3 (5) (2013) 1725-1738.

[12] S. Minakhina, R. Steward, Genetics 174 (1) (2006) 253-263.

[13] A. Basset et al., Proc. Natl. Acad. Sci. USA 97 (7) (2000) 3376-3381.

[14] A. Basset et al., EMBO Rep. 4 (2) (2003) 205-209.

[15] N. Vodovar et al., Proc. Natl. Acad. Sci. USA 102 (32) (2005) 11414-11419.

[16] N. Vodovar et al., Nat. Biotechnol. 24 (6) (2006) 673-679.

[17] O. Opota et al., PLoS Pathog. 7 (9) (2011) e1002259.

[18] M.R. Galac, B.P. Lazzaro, Microbes Infect. 13 (7) (2011) 673-683.

[19] N.T. Nehme et al., PLoS Pathog. 3 (11) (2007) e173.

[20] M.O. Fauvarque et al., Microb. Pathog. 32 (6) (2002) 287-295.

[21] Y. Apidianakis et al., Proc. Natl. Acad. Sci. USA 102 (7) (2005) 2573-2578.

[22] A. Shiratsuchi et al., J. Biol. Chem. 287 (26) (2012) 21663-21672.

[23] C. Kocks et al., Cell 123 (2) (2005) 335-346.

[24] N. Buchon et al., Proc. Natl. Acad. Sci. USA 106 (30) (2009) 12442-12447.

[25] M.S. Dionne, N. Ghori, D.S. Schneider, Infect. Immun. 71 (6) (2003) 35403550.

26] M.S. Dionne et al., Curr. Biol. 16 (20) (2006) 1977-1985.

[27] M. Gottar et al., Cell 127 (7) (2006) 1425-1437.

[28] S. Niehus et al., Fly (Austin) 6 (3) (2012) 193-204.

[29] P. Genevieve, Parasitoids of Drosophila. Advances in Parasitology, vol. 70, 2009: Academic Press, 1-381.

[30] N. Boulanger et al., Insect Biochem. Mol. Biol. 31 (2) (2001) 129-137.

[31] J.C. Castillo, U. Shokal, I. Eleftherianos, Virulence 3 (3) (2012) 339-347.

[32] P. Dobes et al., Fly (Austin) 6 (2) (2012) 75-79.

[33] B. Arefin et al., J. Innate Immun. 6 (2) (2014) 192-204.

[34] P. Tzou, E. De Gregorio, B. Lemaitre, Curr. Opin. Microbiol. 5 (1) (2002) 102110.

[35] M. Gendrin et al., PLoS Pathog. 5 (12) (2009) e1000694.

[36] B. Lemaitre, J.M. Reichhart, J.A. Hoffmann, Proc. Natl. Acad. Sci. USA 94 (26) (1997) 14614-14619.

[37] T. Kaneko et al., Immunity 20 (5) (2004) 637-649.

[38] F. Leulier et al., Nat. Immunol. 4 (5) (2003) 478-484.

[39] N.A. Broderick, B. Lemaitre, Gut Microbes 3 (4) (2012) 307-321.

[40] A.C. Wong, J.M. Chaston, A.E. Douglas, ISME J. 7 (10) (2013) 1922-1932.

[41] J.E. Blum et al. MBio 4 (6) (2013) e00860-13.

[42] M. Hedengren et al., Mol. Cell 4 (5) (1999) 827-837.

[43] F. Leulier et al., EMBO Rep. 1 (4) (2000) 353-358.

[44] P. Georgel et al., Dev. Cell 1 (4) (2001) 503-514. 
[45] M. Gottar et al., Nature 416 (6881) (2002) 640-644.

[46] A. Takehana et al., Proc. Natl. Acad. Sci. USA 99 (21) (2002) 13705-13710.

[47] M.L. Wiklund et al., Dev. Comp. Immunol. 33 (5) (2009) 690-696.

[48] S. Gerttula, Y.S. Jin, K.V. Anderson, Genetics 119 (1) (1988) 123-133.

[49] Z. Kambris et al., Curr. Biol. 16 (8) (2006) 808-813.

[50] F. Leulier et al., Curr. Biol. 12 (12) (2002) 996-1000.

[51] T.M. Rizki, R.M. Rizki, E.H. Grell, Wilhelm Rouxs Arch. Dev. Biol. 188 (2) (1980) 91-99.

[52] M.L. Ruhf et al., Development 128 (8) (2001) 1429-1441.

[53] B. Charroux, J. Royet, Proc. Natl. Acad. Sci. USA 106 (24) (2009) 9797-9802.

[54] A. Defaye et al., J. Innate Immun. 1 (4) (2009) 322-334.

[55] C. Falschlehner et al., Biotechnol. J. 5 (4) (2010) 368-376.

[56] E. Foley, P.H. O’Farrell, PLoS Biol. 2 (8) (2004).

[57] V. Gesellchen et al., EMBO Rep. 6 (10) (2005) 979-984.

[58] D. Kuttenkeuler et al., J. Innate Immun. 2 (2) (2010) 181-194.

[59] D. Bond, E. Foley, PLoS Pathog. 5 (11) (2009).

[60] H. Agaisse et al., Science 309 (5738) (2005) 1248-1251.

[61] M. Rämet et al., Nature 416 (6881) (2002) 644-648.

[62] J.A. Philips, E.J. Rubin, N. Perrimon, Science 309 (5738) (2005) 1251-1253.

[63] A. Avet-Rochex et al., BMC Dev. Biol. 10 (2010).

[64] S.J.F. Cronin et al., Science 325 (5938) (2009) 340-343.

[65] L. Teixeira, Brief Funct. Genomics 11 (5) (2012) 375-386.

[66] M.J. Lee et al., Fly (Austin) 5 (2) (2011) 155-161.

[67] B.R. Graveley et al., Nature 471 (7339) (2011) 473-479.

[68] T.F. Mackay et al., Nature 482 (7384) (2012) 173-178.

[69] M.M. Magwire et al., PLoS Genet. 8 (11) (2012) e1003057.

[70] C. Bokel, Methods Mol. Biol. 420 (2008) 119-138.

[71] J.P. Blumenstiel et al., Genetics 182 (1) (2009) 25-32.

[72] A.C. Spradling, H.J. Bellen, R.A. Hoskins, Proc. Natl. Acad. Sci. USA 108 (38) (2011) 15948-15953.

[73] M.C. LaFave, J. Sekelsky, Genetics 188 (3) (2011) 749-752.

[74] J. Zhong, B. Yedvobnick, Genet. Res. 91 (4) (2009) 243-258.

75] T. Hummel, C. Klambt, Methods Mol. Biol. 420 (2008) 97-117.

[76] K.J. Venken, H.J. Bellen, Methods Mol. Biol. 859 (2012) 203-228.

[77] J.R. Bateman et al., Genetics 193 (2) (2013) 421-430.

[78] H.J. Bellen et al., Genetics 188 (3) (2011) 731-743.

[79] K.J. Venken et al., Nat. Methods 8 (9) (2011) 737-743.

[80] E. Ryder et al., Genetics 177 (1) (2007) 615-629.

[81] K.J. Venken et al., Genetics 186 (4) (2010) 1111-1125.

[82] L.A. Baena-Lopez et al., Development 140 (23) (2013) 4818-4825.

[83] T. Xu, G.M. Rubin, Development 139 (24) (2012) 4501-4503.

[84] C.F. Kao, T. Lee, Cold Spring Harb. Protoc. 1 (1) (2013).

[85] W. Liu, S.X. Hou, Methods Mol. Biol. 450 (2008) 61-70.

[86] C.J. Potter et al., Cell 141 (3) (2010) 536-548.

[87] J.S. Wu, L. Luo, Nat. Protoc. 1 (6) (2006) 2583-2589.

[88] H.J. Motulsky, Prism 5 Statistics Guide, GraphPad Software Inc., San Diego, CA, 2007.

[89] J.K. Herren et al., MBio 4 (2) (2013).
[90] J.E. Lee, I. Edery, Curr. Biol. 18 (3) (2008) 195-199.

[91] E.F. Stone et al., PLoS Pathog. 8 (1) (2012) e1002445.

[92] A.K. Tanenhaus, J. Zhang, J.C. Yin, PLoS One 7 (10) (2012) e45130.

[93] S. Chakrabarti et al., Cell Host Microbe 12 (1) (2012) 60-70.

[94] L. Seroude, Genesis 34 (1-2) (2002) 34-38.

[95] L. Cerenius, B.L. Lee, K. Soderhall, Trends Immunol. 29 (6) (2008) 263-271.

[96] H. Tang, Fly (Austin) 3 (1) (2009) 105-111.

[97] H.J. Nam et al., EMBO J. 31 (5) (2012) 1253-1265.

[98] J.S. Ayres, D.S. Schneider, PLoS Biol. 6 (12) (2008) 2764-2773.

[99] T.M. Rizki, R.M. Rizki, Surface changes on hemocytes during encapsulation in Drosophila melanogaster Meigen, in: A.P. Gupta (Ed.), Hemocytic and Humoral Immunity Immunity in Arthropods, Wiley, 1986, pp. 157-190.

[100] S.C. Wu et al., Cell Host Microbe 11 (4) (2012) 410-417.

101] K.A. Lee et al., Cell 153 (4) (2013) 797-811.

[102] X. Chen et al., Chem. Commun. (Cambridge) 47 (15) (2011) 4373-4375.

[103] F.L. Watson et al., Science 309 (5742) (2005) 1874-1878.

[104] E. Kurucz et al., Curr. Biol. 17 (7) (2007) 649-654.

[105] M. Elrod-Erickson, S. Mishra, D. Schneider, Curr. Biol. 10 (13) (2000) 781-784

[106] A. Garg, L.P. Wu, Cell. Microbiol. 16 (2) (2014) 296-310.

[107] C. Lesch, U. Theopold, Methods to study hemolymph clotting in insects, in: N.E. Beckage (Ed.), Insect Immunology, Academic Press, 2008.

[108] J.C. Paredes et al., Immunity 35 (5) (2011) 770-779.

[109] J. Schindelin et al., Nat. Methods 9 (7) (2012) 676-682.

[110] J.M. Reichhart et al., EMBO J. 11 (4) (1992) 1469-1477.

[111] P. Manfruelli et al., EMBO J. 18 (12) (1999) 3380-3391.

[112] B. Lemaitre et al., Proc. Natl. Acad. Sci. USA 92 (21) (1995) 9465-9469.

[113] S. Vidal et al., Genes Dev. 15 (15) (2001) 1900-1912.

[114] A. Takehana et al., EMBO J. 23 (23) (2004) 4690-4700.

[115] C. Neyen et al., J. Immunol. 189 (4) (2012) 1886-1897.

[116] N. Lhocine et al., Cell Host Microbe 4 (2) (2008) 147-158.

[117] A. Kleino et al., J. Immunol. 180 (8) (2008) 5413-5422.

[118] K. Aggarwal et al., PLoS Pathog. 4 (8) (2008) e1000120.

[119] T. Michel et al., Nature 414 (6865) (2001) 756-759.

[120] E. De Gregorio et al., EMBO J. 21 (11) (2002) 2568-2579.

[121] C. Scherfer et al., Dev. Biol. 323 (2) (2008) 189-196.

[122] C. Lesch et al., Dev. Comp. Immunol. 31 (12) (2007) 1255-1263.

[123] C. Bajzek et al., J. Insect Physiol. 58 (10) (2012) 1376-1381.

[124] J. Colombani et al., Cell 114 (6) (2003) 739-749.

[125] E. Kurucz et al., Proc. Natl. Acad. Sci. USA 100 (5) (2003) 2622-2627.

[126] K. Bruckner et al., Dev. Cell 7 (1) (2004) 73-84.

[127] B. Stramer et al., J. Cell Biol. 168 (4) (2005) 567-573.

[128] J.R. Crew, P. Batterham, J.A. Pollock, Dev. Genes Evol. 206 (8) (1997) 481-493.

[129] T. Tokusumi et al., Genesis 47 (11) (2009) 771-774.

[130] K. Makhijani et al., Development 138 (24) (2011) 5379-5391.

[131] O. Binggeli et al., PLoS Pathogens (2014) in press.

[132] B. Kari et al., J Immunol Methods 398-399 (2013) 76-82.

[133] V. Honti et al., Fly (Austin) 7 (4) (2014) 263-266. 